\title{
TOTAL DOMINATION MULTISUBDIVISION NUMBER OF A GRAPH
}

\author{
Diana Avella-Alaminos ${ }^{1}$, Magda Dettlaff ${ }^{2}$ \\ Magdalena Lemańska ${ }^{2}$ And Rita Zuazua ${ }^{1}$ \\ ${ }^{1}$ Universidad Nacional Autónoma de México, Mexico \\ ${ }^{2}$ Gdańsk University of Technology, Poland \\ e-mail: avella@matematicas.unam.mx \\ mdettlaff@mif.pg.gda.pl \\ magda@mif.pg.gda.pl \\ ritazuazua@ciencias.unam.com
}

\begin{abstract}
The domination multisubdivision number of a nonempty graph $G$ was defined in [3] as the minimum positive integer $k$ such that there exists an edge which must be subdivided $k$ times to increase the domination number of $G$. Similarly we define the total domination multisubdivision number $\operatorname{msd}_{\gamma_{t}}(G)$ of a graph $G$ and we show that for any connected graph $G$ of order at least two, $\operatorname{msd}_{\gamma_{t}}(G) \leq 3$. We show that for trees the total domination multisubdivision number is equal to the known total domination subdivision number. We also determine the total domination multisubdivision number for some classes of graphs and characterize trees $T$ with $\operatorname{msd}_{\gamma_{t}}(T)=1$.
\end{abstract}

Keywords: (total) domination, (total) domination subdivision number, (total) domination multisubdivision number, trees.

2010 Mathematics Subject Classification: 05C69, 05C05, 05 C99.

\section{REFERENCES}

[1] H. Aram, S.M. Sheikholeslami and O. Favaron, Domination subdivision number of trees, Discrete Math. 309 (2009) 622-628. doi:10.1016/j.disc.2007.12.085

[2] S. Benecke and C.M. Mynhardt, Trees with domination subdivision number one, Australas. J. Combin. 42 (2008) 201-209.

[3] M. Dettlaff, J. Raczek and J. Topp, Domination subdivision and multisubdivision numbers of graphs, submitted. 
[4] O. Favaron, H. Karami and S.M. Sheikholeslami, Disproof of a conjecture on the subdivision domination number of a graph, Graphs Combin. 24 (2008) 309-312. doi:10.1007/s00373-008-0788-6

[5] T.W. Haynes, S.T. Hedetniemi and P.J. Slater, Fundamentals of Domination in Graphs (Marcel Dekker Inc., New York, 1998).

[6] T.W. Haynes, S.T. Hedetniemi and L.C. van der Merwe, Total domination subdivision numbers, J. Combin. Math. Combin. Comput. 44 (2003) 115-128.

[7] T.W. Haynes, M.A. Henning and L.S. Hopkins, Total domination subdivision numbers of graphs, Discuss. Math. Graph Theory 24 (2004) 457-467. doi:10.7151/dmgt.1244

[8] T.W. Haynes, M.A. Henning and L.S. Hopkins, Total domination subdivision numbers of trees, Discrete Math. 286 (2004) 195-202. doi:10.1016/j.disc.2004.06.004

[9] H. Karami, A. Khodkar, R. Khoeilar and S.M. Sheikholeslami, Trees whose total domination subdivision number is one, Bull. Inst. Combin. Appl. 53 (2008) 56-57.

[10] S. Velammal, Studies in Graph Theory: Covering, Independence, Domination and Related Topics, Ph.D. Thesis (Manonmaniam Sundaranar University, Tirunelveli, 1997).

Received 13 January 2014

Revised 16 August 2014

Accepted 16 August 2014 